\title{
«El otro yo» de la reina. Reflejos, simulacros y ficciones novohispanas
}

\section{«The other me» of the Queen. Reflections, Simulations and Inventions from New Spain}

\section{Francisco Montes González}

http://orcid.org/0000-0002-0488-7281

Universidad de Sevilla

ESPAÑA

fmontes@us.es

[Hipogrifo, (issn: 2328-1308), 9.1, 2021, pp. 567-580]

Recibido: 17-11-2020 / Aceptado: 12-01-2021

DOI: http://dx.doi.org/10.13035/H.2021.09.01.33

Resumen. El papel de las virreinas en las dinámicas cortesanas de la Nueva España ha pasado prácticamente desapercibido hasta tiempos recientes. En este artículo se analizarán las representaciones simbólicas que tuvieron como protagonista a Juana Díez de Aux y Armendáriz, marquesa de Cadereita, y esposa del virrey novohispano Francisco Fernández de la Cueva. Para ello serán abordados tres aspectos fundamentales: la recreación figurativa en la entrada triunfal, las estrategias de persuasión en los acontecimientos festivos y, por último, el significado de un retrato familiar inédito ejecutado a modo de exvoto religioso con connotaciones propagandísticas.

Palabras clave. Estrategias; imagen; rituales; política; virreina.

Abstract. The role of vicereine into the courtier dynamics of the New Spain has gone virtually unnoticed until recent times. This article will analyze the symbolic representation featuring Juana Díez de Aux y Armendáriz, marchioness of Cadereita and wife of the viceroy of New Spain Francisco Fernández de la Cueva. For this, three fundamental aspects will be approached: the figurative recreation in the 
triumphal entry, the strategies of persuasion in festive events and, finally, the meaning of an unpublished familial portrait executed as a religious votive offering with propagandistic connotations.

Keywords. Strategies; Image; Rituals; Politics; Vicereine.

Juana Francisca Díez de Aux y Armendáriz era la única descendiente de Lope Díez de Aux y Armendáriz, I marqués de Cadereita, y de Antonia de Sandoval y Afán de Ribera, III condesa de la Torre. Nació en Sevilla y al poco tiempo se instaló en la corte madrileña para formar parte del séquito de meninas de la reina Isabel de Borbón. Heredó todas las posesiones y títulos familiares, lo que la convirtió en una de las aristócratas más influyentes de su época. Fruto de la política de estrategias matrimoniales, se casó con el primogénito de la Casa Ducal de Alburquerque, el 12 de enero de 1645 en la capilla del Alcázar Real de Madrid. Así los años anteriores a la partida a México en 1653 junto a la hija de ambos Ana Rosalía de la Cueva, transcurrieron para la marquesa entre las casas principales de la plazuela de la Encarnación en Madrid y el castillo de Cuéllar, feudo principal del señorío, mientras que el duque aumentaba su reputación cosechando éxitos militares en las campañas contra los enemigos de la Corona'. De regreso de tierras americanas pasó al virreinato de Sicilia y al enviudar en el año 1676 ocupó el cargo de Camarera Mayor de las dos reinas consortes de Carlos II hasta su muerte en el Alcázar madrileño el 15 de septiembre de 1696. Fue calificaba de «instruida y literata, y de muy española», resistiéndose a los gustos afrancesados predilectos en ambas soberanas. La estrecha amistad con el duque de Medinaceli, valido regio, le hizo gozar de gran influencia logrando el casamiento de la hija de éste, Juana de la Cerda y Aragón, con su nieto el $X$ duque de Alburquerque y futuro virrey de la Nueva España $(1702-1710)^{2}$.

\section{De penélope a belona: La APARIENCIA Figurada}

A la llegada de una virreina a la Nueva España, esta sería cumplimentada con las prerrogativas debidas aunque siempre se mantendría al margen de la expectación suscitada por su esposo. La pareja nunca compartía el mismo transporte pues, para mayor comodidad, ella ocuparía una litera enviada por el obispo de Puebla, y si tuvieran que avanzar juntos a pie, se mantendría al lado derecho del virrey evidenciando así «la majestad conferida» mientras tomaba posesión simbólica del territorio. Cuando avistaban una población, se adelantaría con su séquito siendo agasajada por las damas principales del lugar hasta que era ubicada en un balcón

1. En un reciente artículo, Sanzsalazar se detiene en analizar las hazañas protagonizadas durante la Guerra de los Treinta Años, en particular su controvertida participación en 1643 en la batalla de Rocroi y en la defensa victoriosa de los sitios de Tortosa y Barcelona entre 1648 y 1652 contra el ejército francocatalán. Asimismo, da a conocer un retrato flamenco inédito pintado como General de Caballería de Flandes. Ver Sanzsalazar, 2020, pp. 62-90.

2. Los escasos datos biográficos proceden de López-Cordón Cortezo, 2003, pp. 148-149. Ver también Rubio Mañé, 1983, pp. 250-251; Fernández de Béthencourt, 1920, p. 291 
de las casas capitulares para contemplar la solemne entrada pública. Una vez en la capital se aposentaría en la residencia de Chapultepec a la espera del último desfile triunfal que observaba desde la morada del marqués del Valle de Oaxaca ${ }^{3}$. Desplazada siempre a un lugar secundario de cierta preponderancia, la virreina se posicionaba en un espacio público de visibilidad que en su justa medida, según Farré, «no eclipsara la preeminencia de su marido como mandatario político»4.

La fama adquirida por el duque de Alburquerque en sus contiendas europeas sirvió de pretexto ideal a los creadores de las escenografías diseñadas en el recibimiento de la capital novohispana, pues en clave metafórica ensalzarían su papel como «héroe político» dispuesto a afrontar los retos de la administración virreinal. Siguiendo la práctica establecida de parangonar la trayectoria y las cualidades de los mandatarios con figuras mitológicas, tanto el programa iconográfico como el discurso retórico ideado en el primero de los arcos patrocinado por la ciudad giraron en torno a la figura de Ulises ${ }^{5}$. De igual modo, más allá de la exaltación del noble convertido en el personaje homérico, también se dio pie a que la virreina, esta vez poseedora por derecho propio de un relevante status social, luciera transformada en su amada Penélope. Con un aparente protagonismo sería rescatada del segundo plano al que quedaba relegada como mera espectadora siendo aclamado el influyente papel que pudiera tener como mediadora en los asuntos de gobierno ${ }^{6}$.

De este modo, en uno de los cuadros de la primera fachada, que estaba rematada con las heráldicas de los Alburquerque y de los Cadereita flanqueando el escudo real, se simbolizó la igualdad de ambos para la virtud y la nobleza. Razona el autor sobre la idea de la grandeza resultante por la unión de dos de las estirpes nobiliarias más poderosas, y de la que será responsable la virreina gracias a la fidelidad conyugal. La escena representaba un carro triunfal tirado por cuatro cisnes, símbolo de la pureza, con Júpiter y Mercurio en la parte trasera portando el primero un cetro y un águila con el escudo de los Alburquerque y el segundo el caduceo y la misma ave con la heráldica de los Cadereita. En la popa iba la duquesa con el

\footnotetext{
3. Chiva Beltrán, 2012, pp. 101-102.

4. Farré Vidal, 2007, p. 121.

5. El impreso fue titulado Elogio panegírico y aclamación festiva. Diseño triunfal y pompa laudatoria de Ulises verdadero. Sobre el significado de este arco véanse entre otros: Farré Vidal, 2005, pp. 672-678 y Rodríguez Moya, 2007, pp. 237-242. También fue llevada a cabo una recreación del mismo en Montes González, 2016, pp. 96-107.

6. Se han documentado casos similares donde la virreina fue incorporada al repertorio festivo. Además se repetirá el tema del emparejamiento mitológico, como en los virreyes marqueses de Mancera actuando de Eneas y Lavinia. Entre los ejemplos más curiosos sobresalen los de la condesa de Paredes elogiada por Sor Juana Inés de la Cruz y Sigüenza y Góngora y el la virreina Luisa de Ahumada siendo retratada junto al marqués de las Amarillas en el arco catedralicio erigido por la catedral de Puebla de los Ángeles. Ver Rubial García, 2014, pp. 8-11.
} 
rostro cubierto por un telliz transparente, en clara alusión al que usó Penélope en la ausencia de Ulises. A su lado, se pintó al duque a caballo sosteniéndola de la mano en recuerdo de las conjeturas de su madre sobre los deseos de acompañar a su esposo?

La otra composición se hallaba en el cuadro central del tercer cuerpo de la segunda fachada y estaba dedicada en exclusiva a celebrar «las ilustrísimas prendas» de la duquesa de Alburquerque, «tan digna consorte de nuestro Príncipe, como feliz esperanza de la sucesión de su estado». Para ello se recurrió al oráculo que profetizó a Penélope como pareja de Ulises, cuya prudencia y justicia pedían «maridaje con la pureza, y virtud» de ésta. Quiso también ponerse de manifiesto la admiración causada por la hermosura de la joven griega entre sus pretendientes, que encontraba un fiel reflejo en la marquesa «por las prendas del cuerpo, y por las dotes del alma». Señala el autor que si las tres Gracias se vieron obligadas a rendirse ante la belleza de la diosa Venus, harían lo mismo guiadas por Mercurio reconociendo además en la dama las virtudes que a esta le faltaban y debían imitar ${ }^{8}$. Así se pintó el Oráculo de Mercurio con la marquesa siendo reverenciada por las tres Gracias coronadas con frutos americanos, espigas y olivas que al mismo tiempo les eran ofrecidos por cada una de ellas ${ }^{9}$.

También el cabildo catedralicio mexicano encargó como de costumbre la erección de un arco triunfal en la fachada occidental de su templo. En esta ocasión, las fábulas escogidas en el despliegue visual girarían en torno a Marte, queriendo con ello alabar de nuevo sus victorias en las batallas comandadas por el continente europeo $^{10}$. La virreina también fue homenajeada en la figura de Belona, esposa del dios de la Guerra y, por ello, señala el escritor del impreso, «ajustadísimo símbolo de la Excelentísima Señora, hija del Neptuno Español, que tanto imperio tuvo sobre tuvo sobre los mares, el Excelentísimo Señor Marqués de Cadereita» ${ }^{11}$.

En el tablero central del segundo cuerpo del arco se trazó un homenaje a la pareja virreinal. Si Marte se casó con Belona para que entre sus muchas victorias no le faltase una compañera con la que «partir aplausos, para acreditar lucimien-

\footnotetext{
7. Pudieron ser tenidos en cuenta algunos grabados que muestran a la diosa Venus montada en un carro alegórico tirado por aves. Además, Rodríguez Moya apuntó como referente gráfico el emblema CXCVII de Alciato sobre el pudor de Penélope y el velo como símbolo de amor hacia Ulises (2007, p. 238). 8. El discurso vuelve a señalarla como fiel esposa y garante de fertilidad, siempre sujeta a los designios del marido. En ningún momento se prestará atención a los propios logros que pudiera haber alcanzado gracias a sus habilidades.

9. Acerca de la significación de los frutos representados, el autor dice que «los de la América, porque espera su dicha al amparo de esta Señora [...], de trigo porque de su agrado fía sus aumentos y la tercera de olivas, porque en su benignidad se asegura la paz». Igual que en el caso anterior, también pudo haberse tomado como guía la estampa de Alciato sobre las Gracias incluida en su segundo libro de Emblemas. Ver Rodríguez Moya, 2007, pp. 240-241.

10. Consúltese una reconstrucción del mismo, así como una completa revisión historiográfica del impreso Marte católico en Montes González, 2016, pp. 107-112.

11. Lope Díez de Aux y Armendáriz desempeñó el cargo de virrey de la Nueva España entre 1635 y 1640. Se le denomina Neptuno por su fama de hábil marino y General de los Galeones de la Carrera de Indias. Ver Rubio Mañé, 1983, p. 245.
} 
tos», el virrey escogió a la marquesa distinguida «en la grandeza del ánimo, en la bizarría del espíritu, en la perspicacia del entendimiento, en los dotes del alma, y en las perfecciones del cuerpo». Incluso reconocería el autor que si en algo era tan grande la pompa del virrey se debía al «traer a su lado a tan esclarecida Belona», de la que nuevamente se esperaba la anhelada descendencia masculina que pudiera heredar sus títulos. La secuencia quedó dispuesta con la figura de Marte coronado de flores de lis y armado sobre un dragón saliendo de la puerta de una cueva y, por el otro lado, a Belona con morrión y plumaje en un carro tirado de dos leones ${ }^{12}$. En el ángulo inferior se veía a la Fama volando mientras tiraba con una mano de dos bandas sujetas a los frenos de las dos bestias y en la parte superior la misma figura alegórica con dos coronas de laurel sobre la personificación de los duques en las deidades ${ }^{13}$.

La otra mención a la virreina en su papel de Belona novohispana aparecía en tres de los seis jeroglíficos colocados en el basamento de la estructura. El primero se refería a la capacidad de la diosa para «darle la llave a las ciudades, poniendo en su arbitrio, el abrirlas a la guerra, o cerrarlas a la seguridad de la paz». Mediante el dibujo del brazo de una mujer con una llave enderezada hacia la puerta de un muro se quiso significar que México confiaba su custodia y su felicidad a quien prometía cerrar el paso a toda adversidad y abrirlo a la buena fortuna. Según la tradición, Belona fue pintada con rayos de Sol siendo la responsable de producir en la tierra los metales y las piedras preciosas. Plasmada esta visión en el segundo emblema, se esperaba que con la llegada de la marquesa, el reino cobraría «cierto lustre y esplendor» y sería más lucido por su asistencia que por sus riquezas. La leyenda contaba que frente al templo de Belona había una columna de cristal a la que se subía la diosa para arrojar una lanza hacia el lugar predestinado a la guerra. En el tercer cuadro se pintó a una ninfa sobre un pilar arrojando un venablo contra los sublevados del Gran Norte y con la otra esparciendo flores hacia un México pacificado ${ }^{14}$.

\section{El PROTAGONISMO FESTIVO: ESTRATEGIAS DE PERSUASIÓN}

Si se hiciera una revisión historiográfica de la trayectoria seguida por todas las virreinas novohispanas resultaría llamativa la escasa atención prestada hasta el momento a este asunto ${ }^{15}$. La justificación se fundamenta en la escasez de fuentes documentales y en la necesidad de profundizar aún más en las existentes mediante

12. En cuanto a la composición, existe un grabado de Bloemaert con la diosa Cibeles sobre un carro tirado por leones y rodeada de figuras alegóricas que coincide en gran parte con la escena descrita. La cueva y el dragón son símbolos propios de los Alburquerque. En cuanto a Belona, véanse entre otras las afamadas interpretaciones de Rubens y Rembrandt con los mismos atributos.

13. En una tarja se leía el siguiente epigrama: «Marte español valiente, y belicoso / de tan sacra Belona conducido, / en Europa dejastes lo vencido, / y a México traéis lo victorioso».

14. Cada uno de estos se completó con su correspondiente mote y rima más un soneto alegórico final. 15. La única monografía dedicada a la virreina María Francisca de la Gándara fue escrita por José de Jesús Núñez y Domínguez en 1950. En el año 2013, Daniela Pastor Téllez defendió en la Universidad Nacional Autónoma de México la tesis de maestría titulada Mujeres y poder: las virreinas novohispanas de la Casa de Austria. 
la búsqueda de nuevos enfoques. A todo ello se suma la falta de un corpus teórico y de una legislación concreta sobre el cumplimiento de unos roles preestablecidos. Los datos sobre sus vidas privadas se desprenden de los testimonios de autos y la correspondencia, los diarios de noticias y los impresos en los que se hace eco de su asistencia a un determinado acontecimiento festivo ${ }^{16}$.

En el caso concreto de la marquesa de Cadereita, el cronista Guijo informará de la pérdida de un hijo de un mal parto, del fallecimiento y solemne entierro de su recamarera, que había sido una esclava negra de su padre, y del ataque de celos de su marido cuando fue agasajada con excesos en la casa de un notable funcionario $^{17}$. También reportará la muerte de su confesor jesuita, el agasajo ofrecido a la virreina entrante y la visita junto a su hija a las clausuras franciscanas de Santa Clara y San Juan ${ }^{18}$. Esta última será una de las pocas y frecuentes actividades oficiales donde las virreinas serían consideradas «como participantes de lo que pertenece a sus maridos por la representación que hacen de la persona de su majestad» ${ }^{19}$

Cuando se trataba de la asistencia a un acto público, y a pesar de las expectativas creadas, la virreina debía someterse al protocolo dispuesto y ocupar un lugar secundario más discreto y con menos proyección que la de su esposo. En palabras de Farré, «podría decirse que social y, por lo tanto simbólicamente, ejerce su posición pública desde una especie de ocultamiento visible» ${ }^{20}$. Con este trasfondo, se acomodarían una serie de lugares revestidos de un carácter metafórico que permitieran satisfacer dichas necesidades. Junto al popular «balcón de la virreina» del palacio ${ }^{21}$, se levantará a instancia de los duques de Alburquerque un mobiliario particular a modo de tribuna cerrada con celosías de madera desde donde la virreina y su séquito asistirían a los oficios catedralicios. Hubo voces que afirmaron que era "gran amiga del boato y que por su orgullo y altivez, mandó fabricar una jaula para ella y su hija cuando se hicieron las fiestas de dedicación de la primera Catedral» 22 . Sin embargo, en un extenso trabajo pudimos desmitificar la llamada «jaula de las virreinas» y darle un sentido acorde a la verdadera historia desprendida de las fuentes documentales ${ }^{23}$. De ahí que señaláramos que dicha invención fue un intento de trasladar a la Nueva España las mismas pautas de comportamiento peninsulares en lo referente al protocolo eclesiástico seguido por los estamentos privilegiados.

16. A pesar de ello, cada vez son más los estudios que ponen el foco de atención en este tema, destacando, entre otros, los apuntes recogidos por Baena Zapatero (2009) y Rubial García (2014), así como los interesantes artículos de Pastor Téllez (2017) y Arenas Frutos (2010).

17. Guijo, 1953, tomo I, p. 262; tomo II, pp. 20, 43

18. Guijo, 1953, tomo II, pp. 94-139; tomo I, pp. 226-227.

19. Sobre las visitas más destacadas de las virreinas a las clausuras mexicanas y, en concreto, del Festín organizado por las monjas de Santa Clara en honor a la condesa de Paredes es de obligada referencia Farré Vidal, 2009, pp. 9-21.

20. Farré Vidal, 2007, pp. 121-122.

21. Cómez Ramos, 1985. De la marquesa dice Guijo que con motivo de la procesión del traslado a la nueva iglesia conventual de la Concepción, las monjas fueron «a reconocer los balcones de palacio, donde estaba la virreina [...] para que la viese una religiosa devota de ella» (Guijo, 1953, tomo II, p. 36). 22. Núñez y Domínguez, 1950, p. XII.

23. Montes González, 2013. También recogido en Baena Zapatero, 2018, pp. 172-174. 
Como alter ego de la soberana, la marquesa tampoco se manifestaba junto a su esposo e incluso se mantenía escondida para servir de modelo de recato al resto de doncellas. Desempeñaba así un papel trascendental tanto en la conformación como en la representación pública de los códigos sociales y la reproducción del modelo hispánico. Sin embargo, no se descarta que mediante este artificio existiera también un deseo por hacer patente su rango ante el resto de la sociedad.

Baena planteará una serie de ideas reveladoras para entender el complejo papel de las virreinas en la escenificación de la autoridad regia ${ }^{24}$. Al contrario que la soberana no tenía el atributo de ser transmisora de la sangre real ni tampoco ejercería el poder directo por el fallecimiento de su esposo, pues sus facultades solo le venían conferidas por el simple hecho de estar casada con el gobernante. Sin embargo, ostentaba en la corte novohispana un importante papel sociopolítico, ya que su imagen también se asimiló a la representación de la persona real. Existen fuentes que aluden a llamativos episodios acerca de esta especie de «transfiguraciones» en las que la virreina se hacía pasar por la monarca durante complejos rituales. Por ejemplo, con motivo de los sorprendentes fastos organizados en honor del nacimiento del príncipe Felipe Próspero en la primavera del año 1658, las autoridades civiles se dirigieron al aposento de la marquesa, en un significativo simulacro de las dinámicas cortesanas que acontecían en el Alcázar madrileño, para que recibiese las felicitaciones, «rebosando las majestuosas alegrías que pudiese la reina nuestra señora que Dios guarde» ${ }^{25}$. De la misma forma que ésta, concluye Baena, «debía mantener una imagen impoluta, y preservar la honra y el respeto, mostrándose como modelo de todas las cualidades a imitar por el resto de mujeres de la sociedad». Incluso el arzobispo se trasladó «a repetir los plácemes» y allí lo recibió con agrado vestida de tela de azul y hojuela de plata, «cuyo primor de labores, hijas del telar, no dieron licencia, por ociosas, a las guarniciones».

Resulta de un valor excepcional el diario de estos fastos, ya que en él se advierte el comportamiento de la virreina durante el transcurso de las actividades programadas. En primer lugar, acudió con profundo fervor a la celebración del solemne Te Deum desde la tribuna catedralicia luciendo «gran número de esmeraldas, perlas y rubíes». Según el cronista, estos adornos no suplantaban «los naturales de aire, discreción, afabilidad y hermosura de que tan pródiga la dotó la naturaleza siendo fiel retrato su hija Ana, «que deslumbró con iguales aseos». Llama la atención el interés de la marquesa por no pasar desapercibida, pues si una de las noches de la máscara asistió desde el balcón, otro día quiso disfrutar en primera fila y salió al encuentro de su marido en una rica carroza, adornada de todo el lujo y el boato que la situación requería. De forma intencionada, para persuadir la atención del público con un impacto visual efectista, eligió tanto para ella como para su hija una suntuosa vestimenta de seda blanca y plata a juego con el atuendo del virrey. No escatimó el escritor en seguir alabando con descripciones minuciosas las exóticas telas y las magníficas guarniciones que, en señal de distinción, lucieron en sintonía

24. Baena Zapatero, 2009, pp. 104-105.

25. Véase un detenido estudio de los acontecimientos en Montes González, 2016, pp. 187-209. Todas las citas originales proceden del impreso Relación ajustada, Diseño breve..., México, 1658. 
en otras ocasiones, como cuando acudieron a un festejo taurino: «Fue ingenioso el gusto de todo el artificio con que procuró mi Señora la Duquesa hubiese variedad aun en el mismo modo de los vestidos, atavíos, joyas, cadenas, diamantes, piedras [...], variando su Excelencia las galas y aderezos que llevaba un día con las que mi señora doña Ana pulía al día siguiente, arte que a todos admiró, y con razón, pues nunca mejor se vio tan discorde hermandad de galas, aliños y trajes».

\section{UN RETRATO FAMILIAR: ENTRE LA PROPAGANDA DEVOCIONAL Y LA ALEGORÍA POLÍTICA}

En el año 2018 fue exhibida en la sala de exposiciones de la Casa del Cordón en Burgos una desconocida colección de arte virreinal. Del repertorio pictórico destacaba un curioso cobre de pequeño formato $(33 \times 45 \mathrm{~cm})$ con el título San Francisco con donantes atribuido al pintor mexicano Cristóbal de Villalpando y fechado en el siglo XVIII26. La composición está protagonizada por la figura del santo al centro con los brazos abiertos recibiendo con la mano derecha una pequeña talla de la Inmaculada Concepción que le es ofrecida por un caballero militar arrodillado, mientras que con la izquierda entrega el cordón de su hábito a una dama postrada junto a una niña, quienes miran fijamente al espectador. En cuanto al escenario se compone de un fondo neutro de color gris donde se abre una ventana en el lado derecho con la vista de una batalla naval y en el contrario sobresale un rompimiento de gloria del que desciende la paloma del Espíritu Santo.

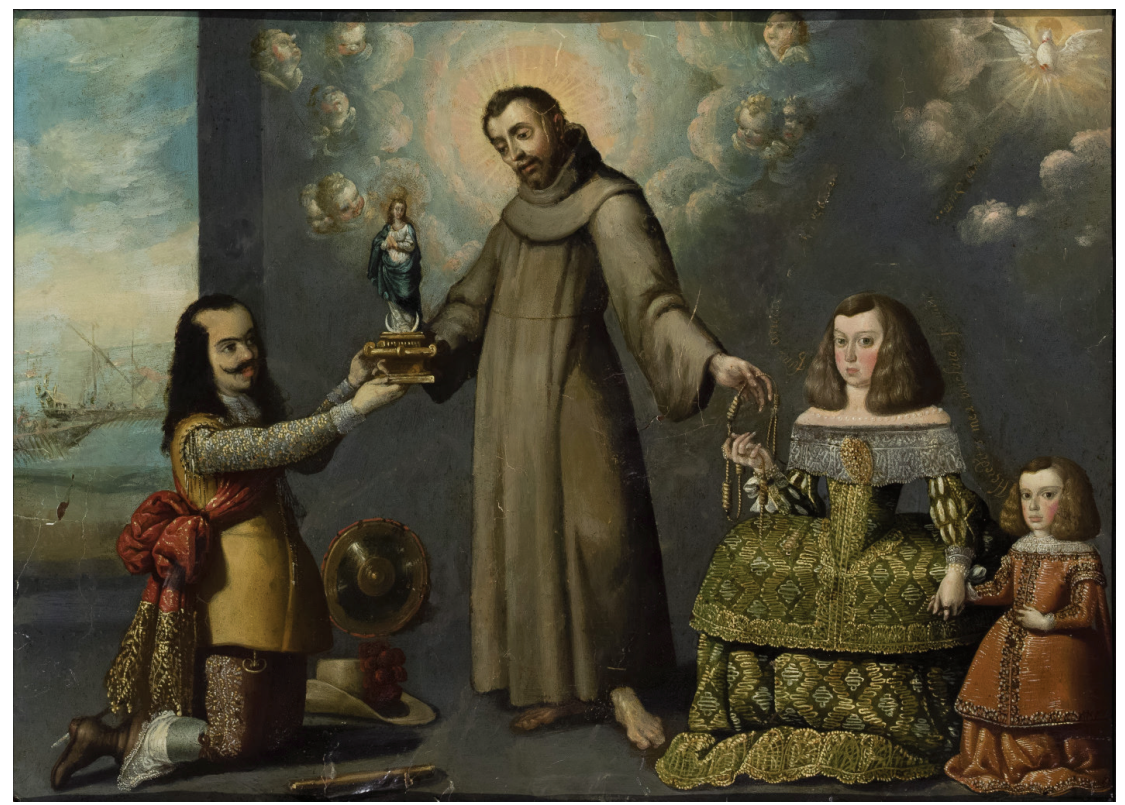

Fig. 1. José Juárez (atribuido a). San Francisco y la familia ducal de Alburquerque. C. 1653-1654. Colección particular. España 
La primera evidencia que ha permitido reconstruir el significado de la imagen ha sido la identificación del personaje masculino con el virrey Francisco Fernández de la Cueva. No hay duda de que sus llamativos rasgos fisonómicos coinciden con los plasmados en sus retratos oficiales destinados a la galería del palacio y del Salón de Cabildos de México ${ }^{27}$. Sin embargo, en este caso aparecerá de cuerpo entero y ataviado con el uniforme de capitán general adornado con la banda carmesí y dispersos a su alrededor el sombrero, la bengala y el escudo. En consonancia con el atuendo, su figura se encuadra con el mismo paisaje bélico que recoge el ejemplar perteneciente al acervo municipal de México y que podría vincularse con su exitosa intervención en los sitios de Tortosa (1648) y de Barcelona (1651-1652) al mando de las galeras españolas ${ }^{28}$.

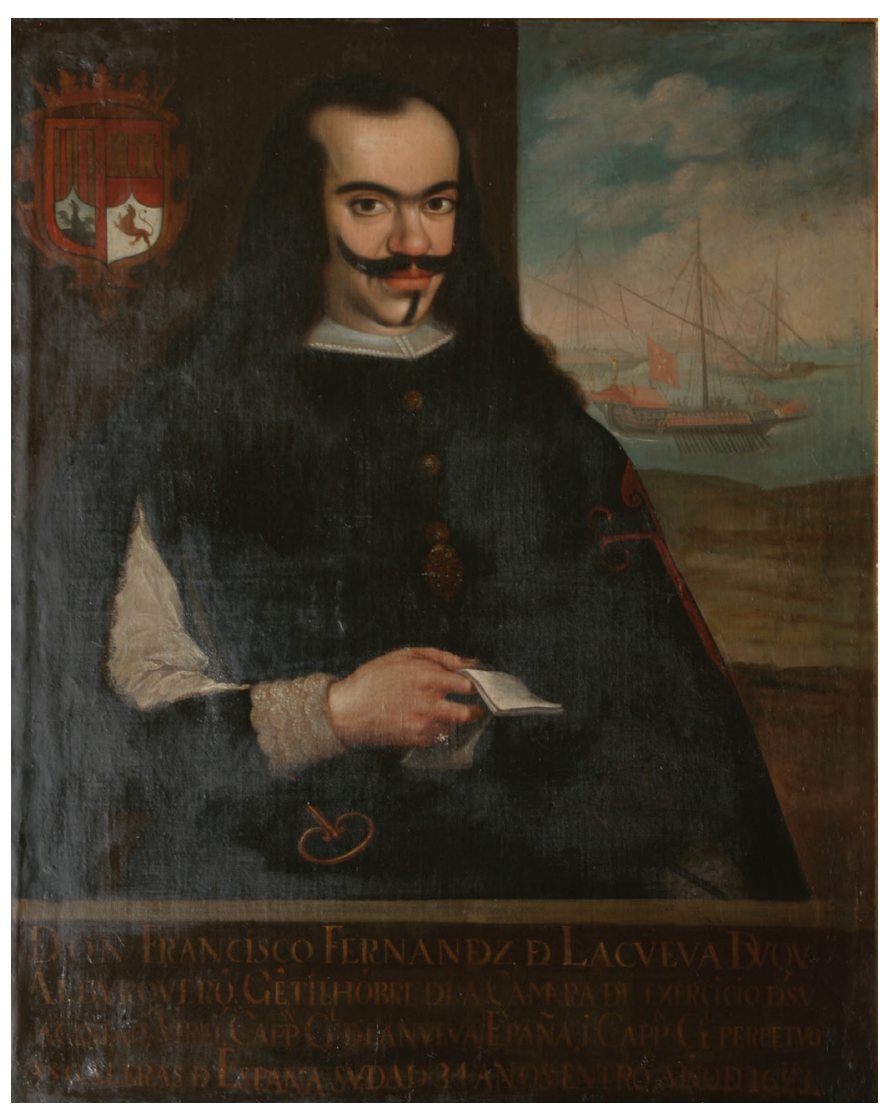

Fig. 2. Anónimo novohispano. Don Francisco Fernández de la Cueva, duque de Alburquerque. C. 1653-1654. Salón de Cabildos. Ciudad de México

27. Rodríguez Moya, 2003, pp. 118, 190.

28. En los fondos del Museo Nacional de Cataluña se conservan sendas vistas de las contiendas con su retrato y una extensa cartela. Ver Sanzsalazar, 2020, pp. 83-84. Además documentamos un grabado novohispano con el duque junto a las tropas frente a las costas catalanas. Ver Montes González, 2016, pp. 113-120. 
Una de las claves que confieren a esta obra un carácter de exvoto sagrado con un trasfondo político se encuentra en la talla mariana que está siendo ofrecida de manera piadosa. Quizás el encargo se justifique en el hecho de conmemorar el logro del voto del juramento concepcionista por parte de las autoridades novohispanas, pues a su llegada el virrey trajo una real cédula de Felipe IV con el mandamiento de que este se produjera de manera inmediata. Bajo su empeño personal dispuso la ceremonia oficial, «a ejemplo de lo que su majestad ordenó en esa corte», y ordenó que los actos litúrgicos se celebrasen en la iglesia conventual de San Francisco dando comienzo el día 4 de octubre de 1653, conmemoración del santo fundador ${ }^{29}$.

Es evidente pensar que completando la jerarquía familiar aparezcan retratadas la virreina y su hija agarradas de la mano ${ }^{30}$. La disposición de ambas, ricamente ataviadas a la moda de la época y postradas mirando al espectador bajo el fulgor de la Gracia divina las convierte en un reclamo prioritario dentro de la escena ${ }^{31}$. De hecho, la marquesa está recibiendo del santo la reliquia de su cordón como muestra de agradecimiento e indicio de la propiedad de este sagrado objeto entre los bienes vinculantes al mayorazgo de la Casa de Cadereita que algún día heredaría la niña ${ }^{32}$. También la participación de la dama en los citados festejos inmaculadistas fue activa ya que ella misma se encargó del último día de la Octava, cuando predicó el comisario general de los franciscanos, principales defensores del dogma, antes de la procesión final. Además, su compromiso espiritual con la regla seráfica no solo se fundamentaba en su onomástica ni en que ostentara junto a su marido el patronato del cenobio de Cuéllar, sino en el hecho de que el 7 de septiembre del mismo año, profesó en la Tercera Orden Seglar durante un acto público llevado a cabo en la capilla correspondiente dentro del complejo mexicano ${ }^{33}$.

Aunque se trata de una composición original sigue el prototipo de la retratística española del barroco donde se retoma la tradición del donante de raigambre medieval ${ }^{34}$. Como apunta Aterido, el comitente, en este caso la duquesa junto a su familia, contempla la presencia sobrenatural de la figura sagrada postrada en actitud reverencia| ${ }^{35}$. En la lámina no solo se manifiesta un profundo fervor franciscano sino un importante éxito compartido en nombre de la Corona que serviría de recordatorio y propaganda del cumplimiento acatado en aquellos territorios. Si-

29. El relato los acontecimientos fue tratado en profundidad dentro de nuestra monografía. Ver Montes González, 2016, pp. 209-216

30. Para no perder la sucesión original del ducado, ya que era de rigurosa agnación, Ana Rosalía de la Cueva se vio obligada a casarse con su tío carnal y legítimo titular Melchor Fernández de la Cueva, con quien tuvo a su primogénito el $X$ duque. Algunos datos biográficos en Fernández de Béthencourt, 1920, pp. 291-295.

31. De la boca de ambas y del resplandor parte unas filacterias en latín a modo de alabanzas que dado el mal estado de conservación de la pieza no han podido ser descritas.

32. Cabe destacar la disposición de los personajes conectados en forma de cadena de transmisión espiritual por la que discurren los logros y beneficios obtenidos de la piedad franciscana.

33. Junto a su marido, fue una gran benefactora de los padres seráficos escogiendo su templo para celebrar solemnidades o simplemente «oír el rezo de las letanías» (1953, tomo I, p. 228; tomo II, p. 39). 34. Un novedoso estudio sobre este género en los virreinatos americanos en Rodríguez Moya, 2018. 35. Aterido, 2006, p. 103. 
guiendo otros ejemplos como las efigies orantes de Felipe IV y Mariana de Austria, atribuidos al círculo de Diego Velázquez y conservados en el monasterio de El Escorial, esta peculiar mezcla de retrato cortesano transformado en ofrenda votiva se podría explicar en función de los usos devocionales del momento y de los deseos de emulación hacia los soberanos.

Un análisis exhaustivo de la obra desde el punto de vista formal ha permitido relacionarla con el pincel del maestro José Juárez. En concreto, el dibujo del santo coincide exactamente con el mismo prototipo empleado en su cuadro de San Francisco recibiendo la redoma sagrada realizado en $1658^{36}$. Junto a las coincidencias estilísticas se observa el tradicional cuidado del artista por la recreación de los espacios y el tratamiento minuciosos de los detalles en las vestimentas. En este momento, Juárez se encontraba en su época de máximo apogeo por lo que es comprensible pensar que se encargara de esta singular pieza al igual que, visto los paralelismos, pudiera haberlo hecho de las efigies del mandatario. De corroborarse su papel como Pintor de Cámara también podría atribuírsele un cuadro inédito de San Juan Bautista que se encuentra en el presbiterio de la iglesia de San Miguel de Cuéllar. Este hipotético obsequio devocional de la virreina coincidiría con el mismo envío de una talla de marfil de su santo patrón para la clausura concepcionista de Ágreda ${ }^{37}$. Por último, la relación de Juárez con el círculo cortesano femenino estaría justificada al ejecutar en 1656 el imponente tríptico guadalupano llevado por su criada Francisca Ruiz de Valdivieso junto a una rica dote de objetos americanos al ingresar de regreso en aquel monasterio. Ya intuyó Sigaut que, entre otras cuestiones, dicha pintura «revela el interesante problema del mecenazgo relacionado con la corte del duque de Alburquerque y de su esposa, la marquesa de Cadereita» ${ }^{38}$.

En los casos analizados en torno a la figura de la marquesa de Cadereita, su papel en la sociedad novohispana no estuvo postergado al de la simple consorte de un gobernante. Cuando la ocasión lo requirió cumplió a la perfección la tarea de encarnar la función simbólica que le confería ser el alter ego de la reina. Ya fuese ocupando los mismos lugares estratégicos o haciéndose retratar en actitudes idénticas, la sociedad novohispana recreó en torno a su figura una serie de invenciones donde se pudo materializar la magnificencia de la monarquía hispánica transferida al territorio americano. Así pues, el simulacro regio reemplazaría la presencia física de la soberana mediante la construcción de una imagen virtual a semejanza de ella. Estas ficciones áulicas quedaron reforzadas gracias a los deseos de la virreina por dejar patente la trascendental significación de su persona como cuerpo político, ya fuese a través de suntuosas apariciones públicas o en misteriosos ritos de ocultamiento.

\footnotetext{
36. Sigaut, 2002, pp. 215-219.

37. También envió un frontal de plata como muestra de afecto personal a la mística Madre fundadora. Ver Montes González, 2016, pp. 248-249.

38. De hecho, gracias al hallazgo del testamento del pintor pudo ser corroborada la implicación del artista en los ámbitos de poder novohispano mediante la relación contractual establecida con sus sucesores, los polémicos condes de Baños. Ver Sigaut, 2002, pp. 214, 238-246.
} 


\section{BiBLIOgRAFÍA}

Arenas Frutos, Isabel, «¿Sólo una virreina consorte de la Nueva España? 16601664. La marquesa de Leyva y II condesa de Baños», Anuario de Estudios Americanos, 67.2, 2010, pp. 551-575.

Aterido, Ángel, «Retrato orante de Mariana de Austria (h. 1655). Taller de Diego Velázquez», en El retrato español en el Prado. Del Greco a Goya, ed. Leticia Ruiz Gómez, Madrid, Museo Nacional del Prado, 2006, pp. 100-103.

Baena Zapatero, Alberto, Mujeres novohispanas e identidades criollas, s. XVI-XVII, Madrid, Ayuntamiento de Alcalá de Henares, 2009. Hay una edición revisada y ampliada, Madrid, Distinta Tinta, 2018.

Chiva Beltrán, Juan, El triunfo del virrey. Glorias novohispanas: origen, apogeo y ocaso de la entrada virreinal, Castelló de la Plana, Universitat Jaume I, 2012.

Cómez Ramos, Rafael, «El balcón de la virreina. Hermenéutica e historia de la arquitectura», Cuadernos de arquitectura virreinal, 1, 1985, pp. 17-24.

Elogio panegírico y aclamación festiva. Diseño triunfal y pompa laudatoria de Ulises verdadero..., impreso en México con licencia, en la Imprenta de Hipólito de Rivera, año de 1653.

Farré Vidal, Judith, «Teatro y poder en el México virreinal: la entrada del duque de Alburquerque en México (1653)», en Actas del Congreso «El Siglo de Oro en el nuevo milenio», ed. Carlos Mata y Miguel Zugasti, Pamplona, Eunsa, 2005, tomo I, pp. 671-679.

Farré Vidal, Judith, «Sobre loas y festines o el elogio a las virreinas en la Nueva España durante la época de Carlos II», en Teatro y poder en la época de Carlos II. Fiestas en torno a reyes y virreyes, ed. Judith Farré Vidal, Madrid / Frankfurt am Main, Iberoamericana / Vervuert, 2007, pp. 117-132.

Farré Vidal, Judith (ed.), Festín plausible con que el Convento de Santa Clara celebró en su felice entrada a la Ex.ma D. María Luisa, Condesa de Paredes, Marquesa de la Laguna y virreina de esta Nueva España, México, El Colegio de México, 2009.

Fernández de Béthencourt, Francisco, Historia genealógica y heráldica de la Monarquía Española... Tomo décimo, Madrid, Estab. Tip. de Jaime Ratés, 1920.

Festín plausible con que el convento de Santa Clara celebró en su felice entrada a la Ex.ma D. María Luisa, Condesa de Paredes, Marquesa de la Laguna y virreina de esta Nueva España, edición, estudio y notas de Judith Farré Vidal, México, El Colegio de México, 2009.

Guijo, Gregorio M. de, Diario de sucesos notables. 1648-1664, tomos I-II, México, Porrúa, 1953. 
López-Cordón Cortezo, M. Victoria, «Entre damas anda el juego: las camareras mayores de Palacio en la Edad Moderna», Cuadernos de Historia Moderna, Anejo II, 2003, pp. 123-152.

Marte católico, planeta de héroes y ascendente de príncipes..., con licencia, en México, por la Viuda de Bernardo Calderón, 1653.

Montes González, Francisco, «La jaula de las virreinas. Polémica en torno a un asiento indecoroso en la catedral de México», en Barroco iberoamericano: identidades culturales de un imperio, ed. Carme López Calderón, María de los Ángeles Fernández Valle e Inmaculada Rodríguez Moya, Santiago de Compostela, Andavira, 2013, vol. 1, pp. 231-247.

Montes González, Francisco, Mecenazgo virreinal y patrocinio artístico. El ducado de Alburquerque en la Nueva España, Sevilla, Real Maestranza de Caballería, 2016.

Núñez y Domínguez, José de Jesús, La virreina mexicana: doña María Francisca de la Gándara Calleja, México, Imp. Universitaria, 1950.

Pastor Téllez, Daniela, Mujeres y poder: las virreinas novohispanas de la Casa de Austria, Tesis de maestría, México, Universidad Nacional Autónoma de México, 2013.

Pastor Téllez, Daniela, «Una virreina comerciante: el caso de la condesa de Galve», Anales del Museo de América, 25, 2017, pp. 195-205.

Rodríguez Moya, Inmaculada. La imagen del virrey. Iconografía del poder en la Nueva España, Castelló de la Plana, Universitat Jaume I, 2003.

Rodríguez Moya, Inmaculada, «Odiseo en la Nueva España. Las virtudes políticas y heroicas del virrey en la decoración de tres arcos triunfales», en Reflexión y espectáculo en la América virreinal, ed. José Pascual Buxó, México, Universidad Nacional Autónoma de México, 2007, pp. 231-257.

Rodríguez Moya, Inmaculada, «Devoción y nación. El retrato de donante en los virreinatos americanos», Norba. Revista de Arte, 38, 2018, pp. 109-131.

Rubial García, Antonio, «Las virreinas novohispanas. Presencias y ausencias», Estudios de Historia Novohispana, 50, 2014, pp. 3-44.

Rubio Mañé, José Ignacio, El Virreinato I, México, Fondo de Cultura Económica / UNAM, 1983.

Sanzsalazar, Jahel, «Encarar el miedo: don Francisco Fernández de la Cueva, VIII duque de Alburquerque (1619-1676), Virrey de Nueva España y de Sicilia...», Philostrato. Revista de Historia y Arte, 7, 2020, pp. 61-98. 
Sigaut, Nelly, «José Juárez: recursos y discursos del arte de pintar», en José Juárez: Recursos y discursos del arte de pintar, catálogo de la exposición, México, Patronato Nacional del Museo de Arte A. C. / Instituto Nacional de Bellas Artes, 2002, pp. 24-282.

VV.AA., Visiones de América. Arte desde el confín del mundo. Colección Francisco Marcos, catálogo de la exposición, Burgos, Fundación Caja de Burgos, 2018. 